\section{High performance solutions, improved patient outcomes}

The Malo Clinic, Lisbon, has provided further evidence that compared to metal prosthetics, high-performance polymer-based solutions made using the JUVORA dental disc from Invibio Biomaterial Solutions indicate improved patient outcomes, including $3 \mathrm{X}$-less bone loss. The JUVORA disc is constructed from PEEKOPTIMA, from Invibio. The Malo Clinic presented these findings at the Congress of the European Association for Osseointegration (EAO), Lisbon, 26 September 2019. This latest study follows earlier findings presented by the Malo Clinic in 2018.

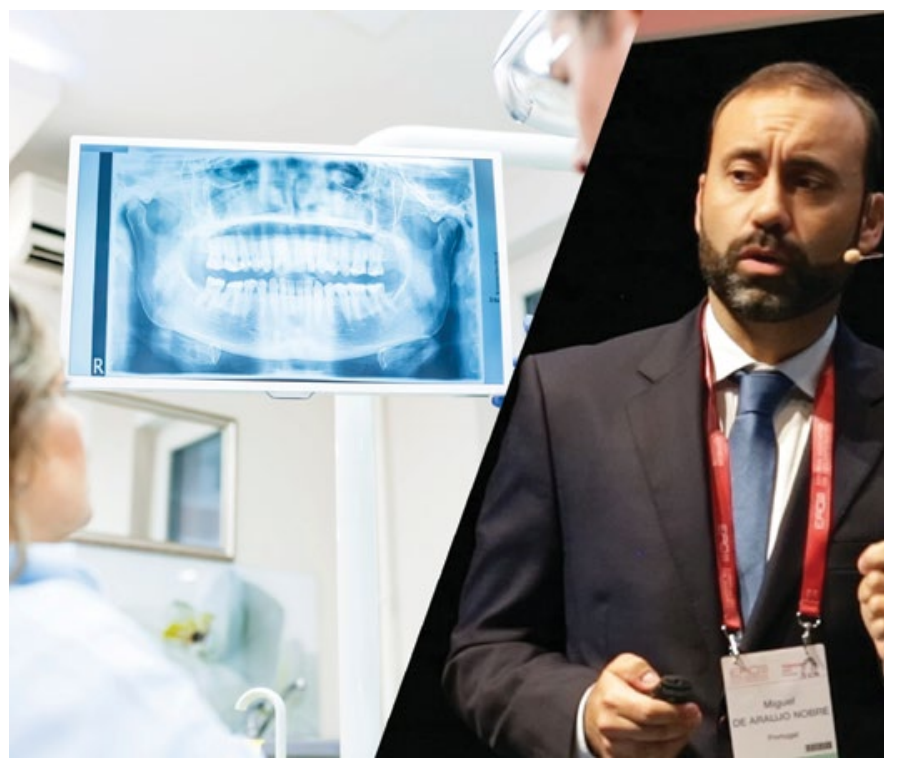

The Malo Clinic's presentation incorporated the results of a threeyear follow-up study of the use of the CAD/CAM-millable JUVORA disc as a substructure for the Clinic's signature All-on-4 procedure, where prostheses supported full-arch implant-supported restorations for edentulous patients.

Specifically, the evidence presented at the EAO in September showed that compared to metal, use of the JUVORA-based prostheses had positive results:

- 3X-lower marginal bone loss

- Peri-implant disease avoided in most patient cases

- Patients reported an improved quality of life

- Absence of correlation between plaque and bleeding

- High implant survival - close to $100 \%$.

PEEK-OPTIMA offers several mechanical benefits over metal frameworks, namely, a more favourable strength-to-weight ratio and the potential for shock absorbtion. Metal prosthetics are naturally stronger; however they are less resilient and can be less comfortable for the patient.

If left untreated, bone loss can lead to pain, infection and loss of lower facial structure as the infection eats away at the jaw bone.

The shock-absorbing properties of PEEK-OPTIMA are explained by its modulus of elasticity, which is very similar to that of cortical bone. When stress transfer is measured against conventional dental materials, PEEK exhibits the most shock absorption.

Further information is available at https://www.invibio.com/dental.

\section{Coming soon: chat}

Dentally is delighted to unveil its plans for a new message capability within Dentally, which allows you to chat easily with your team as part of a commitment to reduce the administrative burden.

Simple, secure and reliable messaging is something that many of us use in our everyday lives. It might be for talking to family, groups of friends, work colleagues or even your child's school through a PC, tablet or mobile device - not to mention Live Chat options on a website. We can all appreciate the need to send a quick reminder to a single contact or within group chat - it is an effective way of ensuring the right information gets to the right people, quickly without the need for yet more admin tasks.

For Dentally, developing an instant messaging system within the software that can help dental practitioners and their teams to chat to one another - just seemed like a simple way of helping dental practices run smoothly, save time and make better decisions. The product development is part of Dentally's ongoing commitment to innovation to reduce the administrative burden on dental practices, that it recently reinforced following the publication of its White Paper: The state of dentistry 2019.

As you would expect from Dentally, it is secure and easy to use. The new chat function means that whether you need to have a discreet conversation about a patient without verbalising sensitive information across the practice, simply pass general information or make a request from the surgery to reception team - you can easily have a focused chat through the messaging service. The impact of this for a practice should not only save valuable admin time but improve efficiencies and productivity among team members.

The new functionality is in its testing phase with a selection of Dentally customers; once that feedback has been used to refine the service it will be rolled out and made available to all dental practices using Dentally for their patient management.

Over 5,000 dental professionals are already working smarter, working remotely and working securely with Dentally, so why not visit dentally.co today to book your free demo or email hello@ dentally.co. Alternatively if you have yet to read the findings of White Paper: The State of Dentistry Report 2019, simply download at https://info.dentally.co/smile-2019.

\section{Get the right support to buy or sell your practice}

For any dentists thinking about selling or buying a dental practice, the experts from Dental Elite were on hand to help at the BDIA Dental Showcase. Whether professionals had questions about the process itself or the services available to them, the team were happy to help.

Dr John Moore recently sold his practice with Dental Elite and commented that he had approached Dental Elite for the sale of his practice upon the recommendation of a colleague. Ted Johnston at Dental Elite kept Dr Moore up-to-date with progress in all aspects he was involved with. Ted was also easy to contact at all hours if Dr Moore had any queries.

For more information on Dental Elite visit www.dentalelite. co.uk, email info@dentalelite.co.uk or call 01788545900. 